\title{
Mechanism Study for E-commerce Affecting China's Future Marketing Mode
}

\author{
Zhenzhen Wang \\ Sichuan Tourism University, Chengdu Sichuan, 610100, China
}

Keywords: E-commerce, Future market, Marketing Mode, Mechanism.

\begin{abstract}
The development of e-commerce to a certain extent changed the traditional concept of consumption and consumption patterns, promoting economic growth, but also affect the business environment to a great extent. At present, during the enterprise development process, they face greater competitive pressure, this time should be reasonable to analyze the impact of e-commerce marketing for the future marketing, and put forward reasonable solutions for this, in order to be able to stabilize the long-term development of the market economy.
\end{abstract}

\section{Introduction}

With the development of computer technology and information technology, electronic commerce have a certain role in promoting. The rapid development of e-commerce has led to a modern market economy needs to face more challenges and opportunities. Including many types of e-commerce, electronic data interchange, electronic mail, online services, electronic transfer, value added network, electronic surveillance and multimedia shopping guide and so on. With the application of information technology to strengthen the level of e-commerce reduces the distance trade, information as an essential element to improve the efficiency of the business to some extent. Establishment of a new business model of the market economy, can effectively understand the industry, the combination of virtual and reality, due to the continuous development of e-commerce, e-business models gradually applied in marketing, improve the speed of the market, expanding the scope of the market, the establishment of a rich marketing.

\section{Development of e-commerce and marketing}

\section{Development of e-commerce}

With the formation of a single type of non-face to face business model development of network technology and information technology, which is e-commerce, a variety of business models can promote a certain extent, enhance trade cooperation, business idea under information model can improve business efficiency, and the organic All sectors combined, unified virtual and reality. Sale terminals retailers, automatic connection function, it is possible to reduce the purchase of artificial links can save labor time and labor. In addition, the new service approach can provide a more comfortable service for customers. Based e-commerce, many companies are able to get more opportunities to break world trade time and geographical constraints, to establish a reasonable relationship of cooperation dealers and suppliers. Information can be formed on the basis of a new economic model, can be an appropriate increase in soft power. From the future development trend, the e-commerce market can be expanded. Due to the continuous development of information technology and computer technology, network information needed to support the practical needs of society. E-commerce model gradually become the inevitable direction of development of the market economy, especially in the face of developed countries and regions, e-commerce can be changed to a 
great extent on the production model to ensure more rational and scientific management of enterprises, which will affect the social economy.

\section{Development of Marketing}

Marketing under the new business activities, according to the enterprise product design labor pricing, sales and operations functions to encourage enterprises to benefit. At this stage, the focus is mainly marketing sensational meet the actual needs of the community, not just say at this stage needs, including potential future needs of society, so for different customer groups, when companies need reasonable application of different types of sales, according to ongoing research to implement corporate marketing new products, in order to guide and stimulate consumption. Marketing campaign is mainly based marketers, product, desires, values, needs, etc., the practical application and analysis when consumers need to understand the psychological and physiological needs, guaranteed according to the perspective of consumers to create consumer demand, thus continue to meet the actual needs of consumers, and also to stimulate consumption, the product is part of a desire production thereof. Based product marketers can continue to meet the desire of consumers choose certain products in the process should have the appropriate selection criteria, which is the value. So when the need for marketing value-conscious, desire, product marketers and other concepts to ensure better able to handle the above-described relationship, and establish a sound marketing program ${ }^{[1]}$.

\section{E-commerce concepts and values}

E-commerce is mainly based on electronic transactions network formation, part of a virtual business. Internet is not restricted by space and time, you can be traded at any time, and be able to complete this transaction online. With the changing market mechanisms, development of the Internet can promote economic and trade development and progress to some extent. Internet can be based on overseas shopping, this approach can improve the speed and more convenient, just in a few seconds to complete. Worldwide consumption of personnel can be based on this approach to online shopping, with stronger directivity, so online shopping is gradually welcomed by all walks of life. With the development of electronic commerce is the inevitable product of the times, it is the combination of high efficiency, simple shopping experience, it is possible to fully meet the actual needs of consumers.

\section{Impact of e-commerce on the future marketing mode}

\section{Change marketing environment}

Internet technology to promote the development of e-commerce, e-business models marketing activities falls under the Internet virtual platform, because to have some virtual, does not suffer from space constraints and marketing, consumers around the world have access to the Internet to purchase their favorite products and based on e-commerce platform to conduct transactions. E-commerce marketing premise, will not be influenced and limited by time, around the clock open e-commerce platform twenty-four hour sales of products, the traditional sales model can change the time limit. Due to the changing marketing activities and marketing, network marketing channels continue to widen significantly increase access to information and means to facilitate the comparison of goods more rational selection of goods, and can get all the product information based on the Internet, as far as possible to reduce intermediate links this method of distribution sales significantly different from the traditional marketing model and proxy mode intermediate portion, not only to promote economic development and business interests, but also to ensure that consumers get more benefits. E-commerce marketing greatly changed the traditional sales model and ideas to improve the global economic growth rate will also affect the operating environment to a great extent, encourage enterprises need to face more pressure, based on this analysis of e-commerce companies should actively to affect the business brings, and the establishment of relevant solutions to address the problem and ensure stable and sustainable development can improve enterprise economy. E-commerce applications can therefore continue to change the way people pay, it is possible to change the traditional way of cash payments, the use of large-scale e-commerce platform to achieve the purposes of third-party payment in order to be able to effectively reduce the cost of market transactions. 


\section{Change consumer behavior and marketing concepts}

With more complex types of goods and items on the Internet platform, when consumers buy goods usually shop around, choose cost-effective products, so as to be able to happy shopping. E-commerce marketing changed to a great extent on the traditional passive consumption, the use of online consumers to choose goods, can expand the choice of space, this independent degrees of freedom can be improved shopping choices, in addition, the consumer is the core of e-commerce, consumer sales path is very important, according to consumer spending data to rationalize the market to ensure the smooth implementation of marketing activities ${ }^{[2]}$.

\section{Change the focus of marketing management}

With the continuous development of e-commerce center, gradually offset marketing, most established e-commerce center is the consumer marketing strategy, based on maximizing consumer to meet market demand, 4G gradually become a key marketing and management, in fact, said communication, convenience, cost, consumption, etc., compared with the original idea for 4P, 4G concept is very concerned about consumer shopping experience, but not the traditional core business of marketing approach. 4G main that is consumer demand, up from the source to tap consumer psychology and consumer demand, in order to be able to fully meet consumer demand. From a cost point of view, we should focus on the relationship between value and price, in-depth analysis of the price, to change the traditional enterprise pricing standard mode. From the perspective of consumer convenience, consumer e-commerce more emphasis on communication, narrow the distance between consumers and businesses, in order to successfully complete the transaction, and promote the development of economic efficiency of enterprises.

\section{Change technology support means}

Customer relationship management is a major component of marketing, it is possible to provide marketing support, customer relationship management can be based on a reasonable convergence databases, multimedia, e-commerce and the Internet, which can also be integrated into the artificial intelligence, to establish a more complete and perfect marketing system, it is possible to develop the marketing service. Customer relationship management can be an appropriate increase in customer satisfaction, ensuring effective protection of consumer interests can be improved to a certain extent on the trading efficiency and reduce costs in order to achieve the purpose of changing marketing environment ${ }^{[3]}$.

\section{Business marketing strategy under E-commerce environment}

\section{Improve business e-commerce credit management mechanism}

Under the premise of e-commerce marketing model to establish more trading platforms, the more important is the credit, so companies should improve their credit management system, in order to continuously improve enterprise credit management companies should be reasonable to conduct market research, understand and analyze consumer , can ensure a more complete enterprise credit management mechanism, in addition, because the internet is established on the basis of the customer relationship, customer relationship information can be recorded in a timely manner on the platform, the establishment of targeted information with a certain data file, also can be appropriately adjusted corporate credit quota to ensure safe and convenient e-commerce transactions, based on third-party payment system for payment transactions, but requires a high degree of national accreditation and certification of third-party payment system.

\section{Innovate marketing concept under the e-commerce foundation}

Progress and development of e-commerce will be appropriate to increase the competitiveness of enterprises, companies want to improve their competitive advantage, we need to continue to analyze the physical and psychological consumers, create new marketing idea, to provide commodity-related information and value to consumers, in order to attract consumer. After a lot of practice can be found, it is possible to establish a more ideal promotional activities on the basis of e-commerce, companies can promote the sales to a certain extent. At this stage, it is compared to traditional shopping, online shopping is still lacking, a majority still choose the traditional way of shopping, resulting in price 
compared to the traditional market, the e-commerce platform product prices are usually relatively low, the adjustment of product prices can increase traffic, in addition, can also be based on the micro-channel, soft, microblogging and other ways to carry on marketing, but also can promote the product development of new products in the online trial, you can expand awareness in order to change the business flow and information flow ${ }^{[4]}$.

\section{Strengthen information system management}

Important way businesses need to constantly improve the information system of personnel training, a culture of information technology personnel, improve the strength of enterprises, according to the actual situation of enterprises to introduce a training mechanism, as the selection and hiring of professionals, according to the independent way of training employees training and joint training can also be combined with reasonable ways to nurture talent. This culture establishing talent mechanism, not only enables companies to innovate and improve the management, operation and production methods and efficiency, but also to a certain extent on the use of experts and scholars to carry out training for employees, can improve their competitiveness to a great extent, promote the pace of enterprise information construction, in order to create favorable marketing conditions.

\section{Rational use of information exchange platform, and implement cross-marketing management} When companies often produced because of the constant changes in consumer spending habits, consumer demand, companies need to understand and master the changing consumer thinking, rationally adjust the pattern of e-commerce platform of products and prices, based on a minimum investment to maximize consumer information data, and data integration and management of the said consumer information under the premise of full understanding of customer needs, based on cross-marketing management have a certain way to build targeted. Meet consumer demand management, in order to be able to meet and continue to achieve market share targets. Enterprises in the deepening understanding of customer needs of the premise, should not only expand the scope of cooperation and exchange of business, guaranteed to constantly improve and perfect their own marketing network, and comprehensively promote economic efficiency ${ }^{[5]}$.

\section{Vigorously develop complex e-commerce marketing professionals}

Compared to the more developed Western countries, the relatively late development of domestic e-commerce and e-commerce is still in the development stage, there is a less complex professionals. Based on the current domestic situation of e-commerce development, efforts should improve the training of personnel, and appropriately invite with a strong practical ability and theoretical knowledge of experts or scholars to be excellent marketing training for employees, for employees to teach marketing services, marketing services awareness and marketing services, technology and other aspects of knowledge and experience, and timely and universities to establish cooperation in the implementation of school-enterprise cooperation training Miou style, corporate culture to understand marketing techniques and knowledge, and have some knowledge of the network and information technology complex talents so that enterprises can ensure the sustainable and healthy development.

\section{Conclusion}

In summary, the development of electronic commerce has been gradually changing socio-economic model, companies need to keep up the pace of development, with the support of information technology and network technologies, innovative products and channel sales prices, guaranteed to fully meet the specifications and requirements of social development, this time need in-depth understanding of e-commerce to business marketing challenges and opportunities, and based on this a reasonable countermeasures to ensure that companies have access to market competitive advantage, to promote healthy and sustainable enterprise development and progress. E-commerce is the main direction of future development, spanning an information age, whether business or self-employed, e-commerce is an enabling mode, to ensure win-win situation.

\section{References}


[1] Zhang Yinke. Discussion on influence of E-commerce on future marketing styles. China E-commerce, 2014(6):8.

[2] Dai Linjun. Discussion on influence of E-commerce on future marketing styles.Business, 2015(23):120-120.

[3] Lin Ping. Influence of E-commerce on future marketing. China E-commerce, 2013(20):6.

[4] Li Na. Study on new strategy of marketing in E-commerce era. Lanzhou Academic Journal,2013(7):207-209.

[5] He Hongyan. Study on new strategy of marketing in E-commerce era. Consumer Electronics, 2014(24):547-547,549. 